\title{
A review of Waste Tyre Rubber as an Alternative Concrete Consituent Material
}

\author{
Kudzai Mushunje ${ }^{1, *}$, Mike Otieno ${ }^{1}$ and Yunus Ballim ${ }^{1,2}$ \\ ${ }^{1}$ University of the Witwatersrand, School of Environmental and Civil Engineering, Johannesburg, South Africa \\ ${ }^{2}$ Sol Plaatjie University, Kimberly, South Africa
}

\begin{abstract}
The current global waste tyre generation far exceeds its consumption in terms of recycling and re-use. The traditional recycling and re-use methods like thermal incineration have proven ineffective, costly and in some cases environmentally unsustainable. Particularly, in developing countries where some of the sophisticated techniques required to process tyres to allow them to be utilised are either too costly or have not yet been developed. The situation has resulted in accumulation of large waste tyre stockpiles that pose health and safety risks. To combat the problem, the use of waste tyre rubber in concrete construction has been proposed. Several studies have been conducted to assess the effects of the inclusion of waste tyre rubber in its different forms (fibres, particles), for concrete production and the results are promising. Although there are some apparent demerits to the inclusion of tyre rubber in concrete, the potential benefits seem to overshadow the negatives. This paper reviews published research on the scientific and technical viability of using waste tyre rubber in concrete production. It discusses the production and properties of waste tyre particles. It highlights advances made with regards to the incorporation of tyre rubber material in concrete, focusing on the engineering properties of the tyre rubber modified concrete. In conclusion, recommendations for future research and possible application for the material will be discussed.
\end{abstract}

\section{Introduction}

Concrete is one of the most extensively used construction material in the world and the natural mineral aggregates used to make the concrete are a finite resource, which is fast dwindling. According to Alexander and Mindess [1] mineral aggregates are the most extensively used material after water and soil. With an estimated total annual global consumption of about 4.5 billion tons, their continued use at this rate is not sustainable given that they are a finite resource. Natural mineral aggregates constitute about $70 \%$ of concrete. This makes aggregates an important constituent in concrete because they have a huge influence on the behaviour of concrete and therefore must be dealt with carefully. The unsustainability of using natural aggregates is not only due to the finite nature of the resources but also due to the huge impact the production of natural aggregates has on the environment. The production of natural aggregates has a huge impact on atmospheric, water and natural environment. Some of these effects span beyond the life of the quarry as the rehabilitation of the land is not always completely successful $[1,2]$. As a result of the need to preserve natural resources and protect the environment, many

\footnotetext{
${ }^{*}$ Corresponding author: Kudzai.Mushunje@students.wits.ac.za
}

other materials have been exploited or use as aggregates in concrete. Several other natural alternatives that have been used include by-products of other processes as such slags, building and construction demolishing material, sawdust, wood wool, rice husks, incinerator residues and clinker ash. Other artificially produced aggregates include bloated clay, shale, glass, fly ash, perlite, exfoliated vermiculite and expanded polystyrene $[2,3]$. The recycling of building materials from demolished buildings like crushed brick and concrete has been receiving a fair amount of attention because of the materials are derived from an aggregate product (concrete) $[4,5]$. The bulk of these alternative materials although they are conservatively referred to as secondary products they are in most cases basically waste materials meant to be discarded. Thus the attractiveness of using most of these alternative aggregates is in their dual purpose. Firstly they reduce amount of waste to be deposed. Secondly, they reduce the amount of virgin aggregate used in concrete. In line with this initiative of using waste materials in concrete, the use of waste tyre rubber particles in concrete has been proposed, mainly as a possible waste tyre disposal method, but research has shown promising concrete 
property enhancements with the use of tyre rubber in concrete with rubber particles known are rubberised concrete or rubcrete.

It is estimated that over 1.2 billion new tyres are produced annually worldwide and disposal at the end of their life has become a major challenge [7]. Annually, Europe and the United States generate 245 million and 270 million waste tyres respectively [6], [8]. The disposal of waste tyres in landfills is a challenge because the tyres tend to rise to the surface during compaction. When stockpiled the tyres are a health risk as they provide breeding ground for rodents and mosquitoes, which may carry diseases [8]. In a bid to curb the risks associated with waste tyre disposal, some countries have passed legislation that governs the disposal of waste tyres in landfills. The European Union directive 1999/31/EC, for example, prohibits the disposal of waste tyres in landfills starting from 2006 [8], [9] The challenge of waste tyre disposal is a global issue, that is affecting both developed and developing countries including South Africa. According to Zvimba et al. [10] South Africa has over 60 million stockpiled waste tyres and this figure increases by about 10 million every year. Mahlangu [11], Banzibaganye [12] and Muzenda [13] report that only $6 \%$ of the waste tyres generated in South Africa are recycled. The Recycling and Economic Development Initiative of South Africa (REDISA) waste management plan has been put in place to ensure that tyres are now being put to useful applications instead of dumping them in landfills [13]. These applications include the shredding of waste tyre to make playground mats, turfs and asphalt concrete. Banzibaganye [12] suggests that the construction industry has the potential to make use of a large portion of the waste tyres generated in South Africa. The use of waste tyre rubber within the construction industry together with the already existing uses for waste tyres may be able to make use of all the waste tyre generated within South Africa and eliminate the issues associated with its disposal. This paper presents a review into the viability of using waste tyre rubber in concrete based on evidence gathered from published literature. The aim is to provide a bird eye's view of the possibility of a concrete with waste tyre rubber as an aggregate.

\section{Tyre Rubber Properties}

\subsection{Tyre Composition}

A tyre is defined as a "continuous pneumatic covering made of natural rubber or synthetic rubber or a combination of natural and synthetic rubber encircling a wheel, whether new, used or retreaded" [14]. Tyres are normally classified according to their use, that is, passenger car tyres, truck tyres and off-the-road tyres (OTR). The material compositions of the three classes of tyres are shown in Table 1. The major differences in composition amongst the tyre classes are the absence of textile fibres and the higher metal material presence in
concrete[6].This

truck tyres than other classes. The rubber content in each of the tyre classes is fairly comparable but the rubber in truck tyres is mainly natural rubber. Truck tyre rubber content is $65 \%$ natural and $35 \%$ synthetic; the opposite is true for other tyres [15].

Table 1: Material Composition of Tyres [16]

\begin{tabular}{|l|c|c|c|}
\hline \multirow{2}{*}{ Ingredient } & \multicolumn{3}{|c|}{ Percentage composition } \\
\cline { 2 - 4 } & Passenger & Truck & OTR \\
\hline Rubber & 47 & 45 & 47 \\
\hline Carbon black & 21.5 & 22 & 22 \\
\hline Metal & 16.5 & 25 & 12 \\
\hline Textile & 5.5 & - & 10 \\
\hline Zinc Oxide & 1 & 2 & 2 \\
\hline Sulphur & 1 & 1 & 1 \\
\hline Additives & 7.5 & 5 & 6 \\
\hline
\end{tabular}

The table provides a basic material composition of tyre material but at a deeper level a typical all-weather tyre has upto 30 variances of synthetic rubber, 8 types of natural rubber and carbon black [16]. This complex material variety in tyre rubber makes it difficult to reuse waste tyres in making new tyres. Tyre manufacturers develop their own unique compounds for specific application in tyre manufacturing; this means no two tyres from different makers are the same.

\subsection{Waste Particle Production}

Waste tyre rubber material added to concrete is generally classified by size rather than use or composition. Though the cut-off sizes for each group differ, authors generally agree on three classes of waste tyre rubber particles [6], [17] The three main classes are shredded / Chipped rubber (13 - $73 \mathrm{~mm})$, Crumb rubber $(0.425-4.75 \mathrm{~mm})$ and Ground rubber $(0.075-0.425 \mathrm{~mm})$ Tyre rubber aggregates are produced from waste tyres by either ambient or cryogenic grinding process. The ambient process is grinding or shredding conducted at room temperature while the cryogenic process, shown in Fig 1 below, entails freezing the tyre under sub-zero temperatures using liquid nitrogen and grinding thereafter [18].

The complete ambient process of making waste tyre rubber particles for use in concrete involves the cutting of the whole scrap tyre diametrically into two halves with the side walls being separated from the threads of the tyre using tyre cutting machines. The slit tyres then undergo primary and secondary shredding to produce tyre shreds or chips. The tyre chips then go through a two stage magnetic separation and screening process, which removes the steel and fibres present in the tyre. The fibre and steel free rubber is then subjected to 
further grinding using special mills that produce the crumb and powder tyre rubber[20], [21].

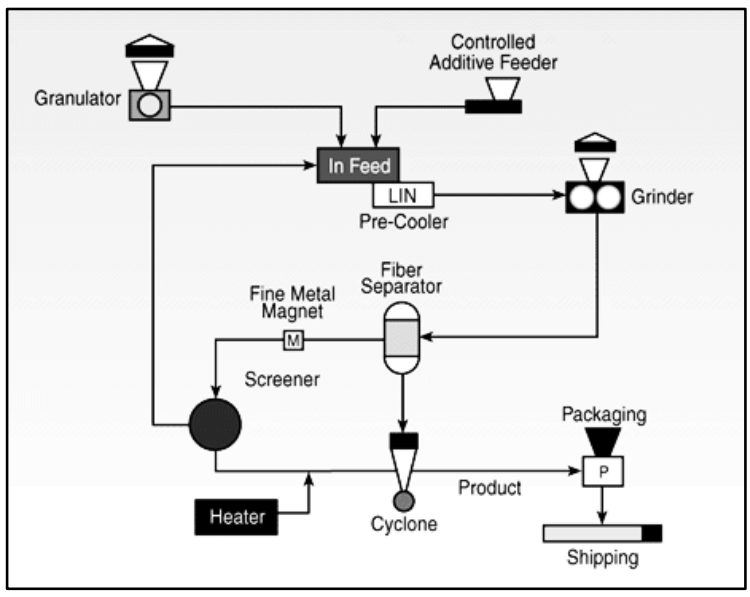

Fig 1, Typical cryogenic tyre rubber particle processing [19]

The process is schematically represented in Fig 2. The ambient process is the most commonly used process because of cost considerations but the cryogenic produces much cleaner tyre rubber particles [22]. The tyre rubber aggregate characteristics depend on the type of tyre used, the region where it was produced and the process used to make the rubber particles [18].

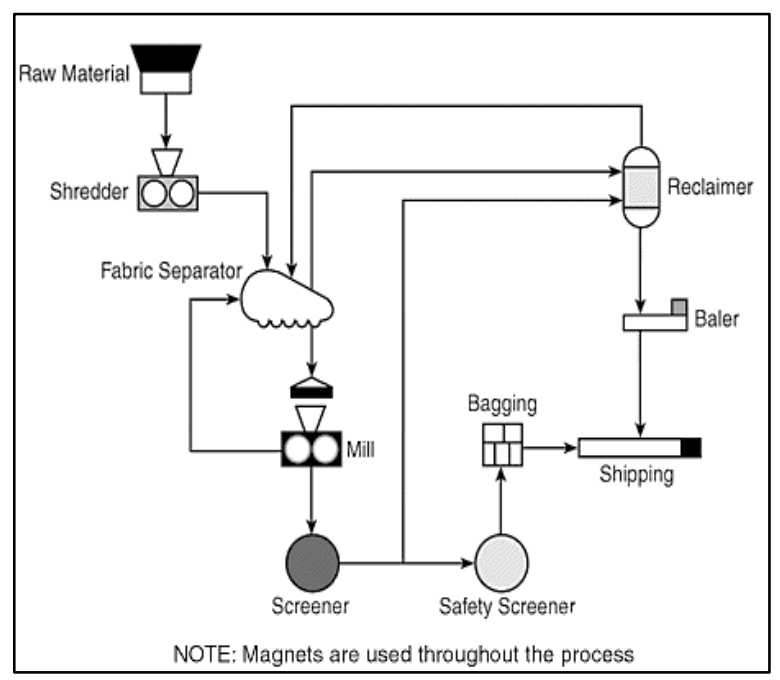

Fig 2, Typical ambient tyre rubber particles process [19]

\subsection{Tyre rubber Particle Properties}

Tyre chips have a loose density is about $320-490 \mathrm{~kg} / \mathrm{m}^{3}$ and a compacted density is about $570-730 \mathrm{~kg} / \mathrm{m}^{3}$ [23]. The specific gravity of crumb rubber is $1.05-1.15$ [24]. The unit weight of rubber particles is much less than that of mineral aggregates thus resulting in a $2-2.5$ times more tyre rubber aggregate volume for the same mass of mineral aggregate. The elastic modulus and Poisson's ratio of tyre rubber particles is $<5 \mathrm{MPa}$ and 0.5 respectively. Tyre rubber particles properties are largely derived from the rubber component of the tyre as it is the major component. These properties can be useful or detrimental to the use of tyre rubber in concrete depending on the application for which the concrete is being made. The effects of tyre rubber in concrete can be controlled in a way that allows for beneficial use of the rubber in concrete. Much research has been done to study how to control these effects by pretreating the tyre rubber particles, varying tyre rubber particles size and shape, limiting the amount of tyre rubber particles in a mix and also using a combination of these control measures. These efforts to control the effects of tyre rubber particles in concrete are detailed in the proceeding section.

\section{Rubberised Concrete Properties}

\subsection{Mechanical Properties}

Research has shown that the presence of tyre rubber aggregates in concrete alters the performance of concrete both, positively and negatively. One major negative effect of using tyre rubber in concrete has been its marked reduction in its mechanical performance compared to conventional concrete. Researchers report notable reductions in the strength and elastic modulus of the rubberised concrete [25]-[28]. The reduction in the mechanical performance has been attributed to the significantly lower stiffness $(<5 \mathrm{MPa})$ of the rubber, the uneven distribution of the rubber aggregate due to its light weight and the poor bonding between the rubber aggregate and the cement paste [17], [26]-[31]. This shortcoming has been tackled but addressing each of supposed causes of the strength reduction.

The lower stiffness of the rubber aggregates was controlled by limiting the amount of tyre rubber aggregates in the concrete and the size of tyre rubber aggregates. Several authors [29], [32], [33] reported that chipped rubber result in greater strength losses compared to crumb rubber. Huang et al. [34] attributed the strength gain that happens when smaller size is used, to the reduction of the stress and strain concentrations in the concrete. The effect of tyre rubber content and rubber aggregate size on the mechanical performance of concrete was assessed by Li et al. [35]. They found that high rubber content and smaller tyre rubber aggregate size reduced both the compressive strength and static young's modulus of rubcrete. However, the ultimate strain of the rubcrete increased as rubber content increased and particle size decreased. In addition to that crack length, width and occurrence decreased with an increase to tyre rubber aggregate content and smaller rubber aggregate size. Their findings concurred with separate studies by other researchers. Thus, with regards to rubber content and size, most researchers have suggested a maximum rubber content of not more than $20 \%$ total aggregate volume and a size no bigger than crumb rubber size. It was imagined that the soft rubber acted like air voids within the concrete thereby offering little resistance to loads thereby rendering the particles site as points of weakness within the concrete matrix.

The lack of bond was addressed by two main approaches. Firstly, by using the rubber particles with 
the steel fibres still embedded that allowing them to be anchor in the paste [8], secondly, by pretreating the surface of the tyre rubber particles. The major surface treatment methods and their percentage strength improvements are shown in Fig 3.

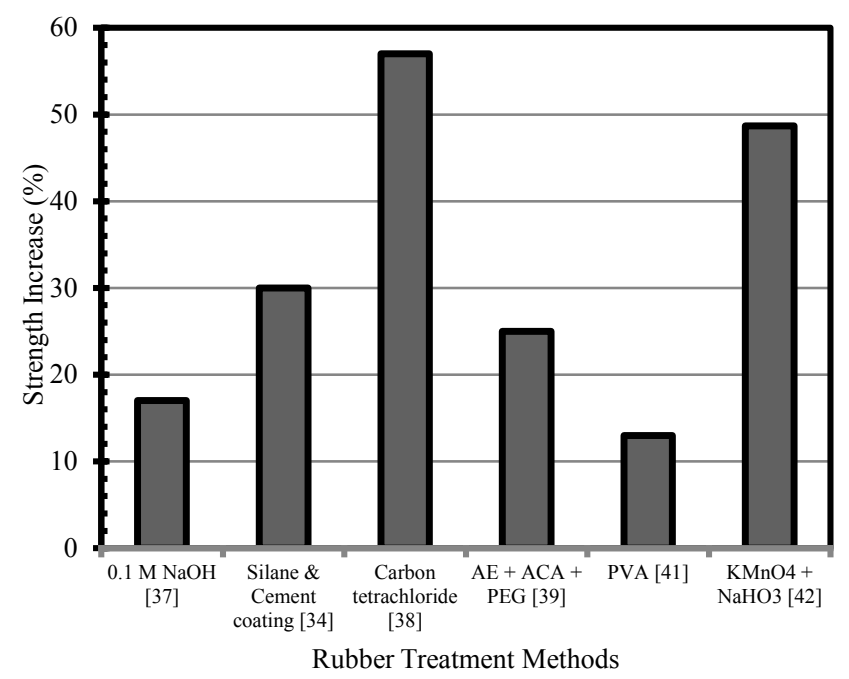

Fig 3, Strength Increase due to Surface treatments

Chou et al.[36] in his investigation pretreated crumb tyres with waste organic sulfur compounds from a petroleum refining factory. $\mathrm{He}$ found that the compressive, tensile, and flexural strengths of concrete samples containing treated rubber particles increased significantly. Segre and Joekes [37] reported an improvement of $17 \%$ in compressive strength when crumb rubber (maximum size 35 mesh) is pretreated with $0.1 \mathrm{M}$ Sodium Hydroxide $(\mathrm{NaOH})$. It was also found that $\mathrm{NaOH}$ surface pre-treatment was better suited for rubber particle size not bigger than crumb rubber. Huang et al. [34] performed a two staged surface treatment to improve properties of rubber modified rubber cement composites. They used silane coupling agent to modify rubber particle surface and then use cement to coat the treated rubber particles. This method is said to result in upto $30 \%$ strength gain. Rostami et al. [38] found that when crumb tyre rubber is pretreated with carbon tetrachloride, the rubberised strength improved by $57 \%$. Haibo et al. [39] reported a $25.4 \%$ strength improvement in compressive strength at $10 \%$ rubber particle content when the rubber particles were treated with analytically pure anhydrous ethanol (AE) solvent, acrylic acid (ACA) and polyethylene glycol (PEG) for grafting hydrophilic groups on their surfaces. Eldin and Senouci [25] in their study prepared their mechanically produced tyre rubber particles by soaking and washing them with water. Albano et al. [40] reports an increase in the compressive and splitting tensile strengths of rubcrete made form crumb rubber pretreated with $\mathrm{NaOH}$ and silane. Balaha et al.[41] found that when crumb rubber was pretreated with polyvinyl alcohol (PVA) and sodium hydroxide $(\mathrm{NaOH})$, strength performance of rubcrete improved significantly. He et al. [42] proposed a pretreatment method to generate strong chemical bonds between the rubber and the cement paste. The crumb rubber particles were polarized by first oxidizing them with Potassium permanganate solution $\left(\mathrm{KMnO}_{4}\right)$ and then sulphonated with Sodium bisulphite solution (NaHSO3). The results showed a $48.7 \%$ strength improvement. The pretreatment method of limiting strength reduction concrete did yield some good results but some of the pretreatment regimes were too impractical for onsite application or even mass application. Some of the chemical are hazardous and have restricted access. This means that the pretreatment approach is mostly limited to experimental investigations. The other limitation with pretreatment is the increase of the cost of production of tyre rubber aggregates due to the additional cost of pretreating with chemicals.

The other approach employed, was the use of various binder types. Some of the suggested binder types include magnesium oxychloride cement, Portland cement blended with fly ash, slag and silica fume. Most of the research has been around the effect of silica fume on the strength gain of rubberised concrete. Biel and Lee [43] noted that the binder type of cement had a significant influence on the compressive strength of rubcrete. They made rubcrete from two types of cement, magnesium oxychloride cement and Portland cement. They found that magnesium oxychloride cement concrete showed about $250 \%$ the compressive strength of portland cement concrete. They suggested a limit of $17 \%$ fine aggregate replacement with crumb rubber if magnesium oxychloride cement was to be used to make high strength concrete for structural applications. Silica Fume has been suggested by some researchers reporting that it significantly improved the compressive and splitting tensile strengths and modulus of elasticity of mixtures particularly in early ages. They note that silica fume influence was more pronounced at high $\mathrm{w} / \mathrm{c}$ ratio. It was found that a $40 \%$ increase in compressive strength was possible for the high $\mathrm{w} / \mathrm{c}$ concretes containing $15 \%$ or $25 \%$ crumb rubber aggregates by volume [44]-[46]. A combination of surface treatment and binder type change has been suggested as the most probable method to produce structural rubcrete. Pelisser et al.[47] made a 48 $\mathrm{MPa}$ strength rubberised concrete, with $10 \%$ crumb rubber to fine mineral aggregate replacement by volume and a $15 \%$ silica fume-cement replacement at a water-tobinder ratio of 0.4 concrete mix. They reported a synergy between the combinations of sodium hydroxide pretreatment and use of $15 \%$ silica fume. A similar synergetic relationship is reported to exist between fly ash and metakaolin with regards to the reduction of strength loss attributed to the presence of waste rubbers [48]. Despite the high strength recorded for the various binders, it must be noted that these compressive strengths were less than those of plain concrete. This in essence means that the binders merely produced a concrete with a higher strength which was reduced in strength when rubber was incorporated only that the reduction was not too high to get the control mix below the plain concrete made with unblended Portland cement. This therefore implies that changing binder type does not improve on rubberised concrete strength but provides a wide range within which strength can fall 
before it can be considered lie outside of structural concrete range.

Overall, however, these different approaches have shown that rubberised concrete make be manipulated to produce whatever strength is desired for any application, from non-structural or structural concrete. This makes the material versatile enough for the construction industry. The suitability of a concrete for structural use is not only dependent on its mechanical performance only but its durability performance must be acceptable.

\subsection{Durability Performance}

Two major durability performance aspects assessed to evaluate the concrete performance in use were carbonation and chloride. Although other durability aspects have been assessed these 2 are presented as they represent typical site environmental loads in normal life of a structure in South Africa that it is possible to produce a structural rubberised concrete. Bravo and Brito [49] investigated the effect of crumb and chipped tyre rubber aggregates produced by ambient and cryogenic processes on carbonation resistance of the concrete. They found that the carbonation depth increased with increase in tyre rubber aggregate volume. They also found that the tyre production method did not influence the carbonation durability performance of the concrete. They reported a decrease in carbonation resistance for chipped rubber when compared to crumb rubber aggregates. They attributed the general higher carbonation depth for rubberised concrete to the higher water content required to achieve a workable mix with rubberised concrete and the increased void volume between tyre rubber particles and the binder. Gupta et al. [50] assessed the carbonation resistance of concrete with tyre rubber particles $(0.15-1.9 \mathrm{~mm})$ at different replacement levels $(0-25 \%)$ and $3 \mathrm{w} / \mathrm{c}$ ratios $(0.35,0.45$ $\&$ 0.55). Their findings concurred with Bravo and Brito [49], and also noted that carbonation depth increased with carbon dioxide exposure for all the water-to-cement ratios and fine aggregate percentage replacements. They also found that reducing the water-cement ratio improved the carbonation resistance of the rubberised concrete. Thomas et al [51] reported an opposite trend to that of Gupta et al [50] and Bravo and Brito [49]. They reported a decrease in carbonation depth for rubberised concrete with crumb rubber aggregate up to $12.5 \%$ replacement. They however report a gradual increase in carbonation depth from $10 \%$ up to $20 \%$ crumb rubber substitution.

Similar studies were carried out on thee chloride resistance of rubberised concrete. The results were also not conclusive. According to Oikonomou and Mavridou [52] the introduction of crumb rubber in concrete mortar improved the chloride ion penetration resistance of the mortar. They found that the lowest rubber content produced a significant reduction in chloride ion penetration when compared to the control mix. The 2.5 $\%$ and $15 \%$ rubber content mixes gave a $14.22 \%$ and $35.85 \%$ respectively. Several other researchers [53]-[55] had similar findings to those of Oikonomou and
Mavridou [52]. Gupta et al. [50], [53] reported a decrease in the chloride diffusion coefficient with an increase in rubber content for all water-cement ratios compared to the reference mix. Onuaguluchi and Panesar [54] replaced $5-10 \%$ by volume of fine aggregate with crumb. They report a reduced charge transmission for all the replacement levels. Li et al. [56] conducted rapid chloride permeability tests for concrete made with treated and untreated rubber aggregates. The rubber aggregates were pretreated with silane coupling agent and carboxylated strene-butadiene rubber latex. They found that for both treated and untreated rubber aggregate mixes there was a decrease in chloride penetration up to a limiting replacement level, $5 \%$ and $15 \%$ for untreated and treated rubber mixes respectively. They report that higher replacement levels result in poor durability performance. Bravo and Brito [49] reported a contrary behaviour. Their chloride migration test showed an increase in chloride diffusion coefficients for the 5\% - $15 \%$ replacement levels of tyre rubber aggregates. They found that the replacement of coarse aggregates with chipped rubber particles resulted in a much higher decrease in chloride penetration resistance as compared to crumb rubber. They also found that aggregate produced by the ambient process had better durability performance than those produced by cryogenic process. Similarly, Gesoglu and Guneyisi [44] reported a continuous decrease in the chloride penetration resistance with increasing crumb rubber content in selfcompacting rubberized concrete. Thomas et al.[57] found that rubberised concrete with up to $10 \%$ crumb rubber by volume replacement level had lower or similar chloride penetration depth and mixes with $12.5 \%-20 \%$ crumb rubber had high chloride penetration compared to control mix.

Although general conclusions can be drawn from theoretical inference depending on what data is used there is very little agreement in research on the effects of rubber on the carbonation and chloride durability performance of rubberised concrete. It would appear that in cases where the research shows high air content in the concrete mix due to the inclusion of rubber the durability performance does decrease, opposite is true for increased durability performance. This suggests that to improve durability in rubberised concrete the amount of air content must be controlled.

\subsection{Enhanced concrete properties}

\subsubsection{Thermal Conductivity}

Ghedan and Hamza [58] used treated and untreated chipped rubber particles to replace coarse aggregates in concrete. They found a reduction in thermal conductivity of $26.7 \%$ for $15 \%$ untreated rubber content and an increase of $17.8 \%$ for treated rubber when compared to the control mix. The treated rubber was treated with SILAN and it also exhibited an increase in compressive when compared with untreated rubberised concrete with 
same rubber aggregate replacement level. Mohammed et al. [59] replaced cement with a combination of $10 \%$ silica fume and fly ash and found that it results in a reduction of the thermal conductivity of rubberized concrete. This is attributed to the thermal conductivity of the materials, which are lower than that of cement. Fiore et al. [60] found that the inclusion of $10 \%$ by volume, of fine rubber aggregate results in a $23 \%$ improvement of thermal insulation. These studies have shown that rubberised concrete containing either chipped or crumb rubber particles exhibit has a lower thermal conductivity when compared to plain concrete. Ocholi et al. [61] in their study of the thermal performance of rubberised concrete, found that the thermal conductivity of concrete ( $1.816 \mathrm{~W} / \mathrm{mk}$ ) had reduced by $29 \%$ to $1.283 \mathrm{~W} / \mathrm{mk}$ at rubber replacement level of $25 \%$. The concrete specific heat capacity also dropped by $30 \%$ for the same rubber replacement level.

\subsubsection{Acoustic Properties}

Rubberized concrete is effective in absorbing sound, impact and vibrations energy compared to plain concrete [62]. Crumb rubber concrete sound absorption properties are better compared to plain. Jedidi et al. [63] found that the sound absorption and noise reduction coefficient increased with an increase in crumb rubber percentage replacement levels. They suggested that the higher sound absorption of rubberised concrete is due to the increase in air voids in the concrete. Holmes et al. [64] investigated the sound absorbance and insulation properties of rubberized concrete at low $(63,125,250 \&$ $500 \mathrm{~Hz})$ and high $(1000,2000,4000,5000 \mathrm{~Hz})$ frequencies. They found that the sound insulation performance of rubberised concrete was comparable to plain concrete for all the replacement levels. They note that the absorption coefficient, however, increased for all replacement levels and for all rubber particle sizes. The crumb rubber concrete was a more effective sound absorbent than plain concrete in different temperature conditions. It was also found that crumb rubber particles produced concrete with better high frequency sound absorption performance because of its higher surface area. Bjevgovic et al. [8] also reported that incorporating rubber in concrete noise barriers increases the sound absorption capabilities of the barriers by $6 \mathrm{~dB}$. FraileGarcia et al. [65] reported that concretes with rubber replacement levels from $20 \%$ were ideal for low frequency sound absorption. While concrete with rubber replacement less than $20 \%$ was ideal for high and medium frequency absorption. They also noted that there was little difference between the sound absorption performance of plain concrete and rubberised concrete with rubber replacement level less or equal to $10 \%$.
There consensus on the positive effect of tyre rubber on acoustic properties of concrete.

\section{Discussion}

The use waste tyre rubber particles in concrete although motivated by a need to dispose of ever increasing waste tyres has become an area of interest to concrete material researchers due to the observed improvement in the thermal insulation, acoustic properties and high strain absorption of concrete. The brief review shows that it is possible to manipulate rubber particles in order to achieve desired concrete strengths. It is not clear however if the same can be done for the durability aspects of the concrete. Although it is apparent that an increase in air content seems to result in low carbonation and chloride durability it is not obvious from literature if this can be limited where tyre rubber is concerned. The challenge with the reduction in air content is that it might result in the reduction of some desired effects associated with the inclusion of tyre rubber in concrete. An example is that when silica fume is used to increase the strength of concrete the thermal conductivity of rubberised concrete is comparable to that of plain concrete. The durability studies have do not give any conclusive trend that can be assorted with a specific feature of the rubber particles. The experiments differ from one researcher to another with a few concurring observations in a few instances. This means a more concerted effort is required to run a set of standardised tests to form a baseline for future tests. From all the literature it however appears that $10 \%$ replacement level of crumb size is the optimum content and size to achieve a satisfactory structural concrete without need for pretreatments and blended cement.

\section{Conclusion}

Although much work has been done to better understand the effects of tyre rubber on concrete properties there is still need for more research. In particular, carbonation and chloride durability. It can be seen from a strength perspective that rubberised concrete can be used for structural applications without many issues. It is apparent from literature that the use of rubber in concrete is a viable option which can make concrete an even more versatile material which can be used for structural applications without the need to load it with cladding for better thermal and acoustic performance.

\section{References}

1. M. Alexander, S. Mindess, Aggregates in Concrete (2015) 
2. G. Owens, Fundamentals of concrete (2013)

3. Graham Grieve, Aggregates for concrete, in Fulton's Concrete Technology, 9th ed (2009).

4. I. Kesegić, I. Netinger, D. Bjegović, Recycled clay brick as an aggregate for concrete: Overview, Tech. Gaz., 3, 35-40 (2008)

5. F. M. Khalaf, Recycling of clay bricks as aggregate in asphalt concrete, in Proceedings of International RILEM Conference on the Use of Recycled Materials in Buildings and Structures, Barcelona, Spain, 1, 56-65 (2004)

6. R. Siddique, T. R. Naik, Properties of concrete containing scrap-tire rubber - an overview, Waste Manag., 24, 6, 563-569 (2004)

7. S. Jain, To Study on Waste Tyre Rubber as Concrete, (2014)

8. D. Bjegovic, S. Lakusic, A. Baricevic, M. Serdar, I. Haladin, 'Innovative use of waste tyres for sustainable concrete technology, in International Advances in Cement and Concrete Technology in Africa, 535-542 (2013)

9. M. Mavroulidou, J. Figueiredo, Discarded tyre rubber as concrete aggregate: a possible outlet for used tyres, Glob. NEST J., 12, 4,359-367 (2010)

10. J. Zvimba, E. Muzenda, N. Nkosi, The Waste Tyre Problem in South Africa: An Analysis of the REDISA Plan, ICCEE (2013)

11. M. L. Mahlangu, Waste tyre management problems in South Africa and the possible opportunities that can be created through the recycling thereof (2009).

12. G. Banzibaganye, Investigation of the use of waste tyre shreds in reinforcement of sandy soils in South Africa (2014)

13. E. Muzenda, A discussion on waste generation and management trends in South Africa, Int. J. Chem. Environ. Biol. Sci., 2,2 (2014)

14. Department of environmental affairs, Integrated Industry Waste Tyre Management Plan of the Recycling and Economic Development Initiative of South Africa, vol. ACT NO. 59 OF 2008. 2012.

15. R. Schnormeir, Recycled Tire Rubber in Asphalt, presented at the 71st Annual Meeting of the Transportation Research Board (1992)

16. A. Evans, R. Evans, The Composition of a Tyre: Typical Components. The Waste \& Resources Action Programme (2006)

17. T. R. Naik, S. S. Singh, Utilization of discarded tires as construction materials for transportation facilities (1991)

18. F. P. Torgal, A. Shasavandi, S. Jalali, Tyre rubber wastes based concrete a review, in WASTES: Solutions, Treatments and Opportunities, (2011)

19. Recycling Research Institute, Scrap Tire (2017)

20. A. A. Hilal, Effect of Crumb Tyres Rubber on Some Properties of Foamed Concrete, Anbar J. Eng. Sci., 4, 2, (2011)

21. A. Akinwonmi, A. Samuel, Seckley, Emmanuel, Mechanical Strength Of Concrete With Crumb And Shredded Tyre As Aggregate Replacement', Int. J. Eng. Res. Appl., 3, 2, 1098-1101 (2013)
22. M. H. Blumenthal, Producing Ground Scrap Tire Rubber: A Comparison Between Ambient and Cryogenic Technologies, in 17th Biennial (1996)

23. P. J. Bosscher, T. B. Edil, N. N. Eldin, Construction and performance of a shredded waste tire test embankment, Transp. Res. Rec., 1345, (1992).

24. M. Heitzman, Design and construction of asphalt paving materials with crumb rubber modifier, Transp. Res. Rec.,1339 (1992)

25. N. N. Eldin, A. B. Senouci, Rubber-Tire Particles as Concrete Aggregate, J. Mater. Civ. Eng., 5, 4, 478-496 (1993)

26. K. S. Malladi, Studies on rubberized cement concrete (2004)

27. L. Zheng, X. S. Huo, Y. Yuan, Strength, Modulus of Elasticity, and Brittleness Index of Rubberised Concrete, J. Mater. Civ. Eng., 20, 11 (2008)

28. M. Elchalakani, High strength rubberized concrete containing silica fume for the construction of sustainable road side barriers, Structures, 1, 20-38 (2015)

30. K. C. Panda, P. S. Parhi, T. Jena, Scrap-TyreRubber Replacement for Aggregate in Cement Concrete: Experimental Study', Int. J. Earth Sci. Eng., 5, 6, 1692-1701 (2012)

31. S. Jain, To Study on Waste Tyre Rubber as Concrete (2014)

32. Z. K. Khatib, F. M. Bayomy, 'Rubberized Portland Cement Concrete', J. Mater. Civ. Eng., 11, 3, 206-213, (1999)

33. lker B. Topçu, N. Avcular, 'Analysis of rubberized concrete as a composite material', Cem. Concr. Res., vol. 27, 8, 1135-1139, 1997.

34. B. Huang, X. Shu, J. Cao, 'A two-staged surface treatment to improve properties of rubber modified cement composites', Constr. Build. Mater., 40, 270-274 (2013)

35. L.J. Li, W.F. Xie, F. Liu, Y.C. Guo, J. Deng, 'Fire performance of high-strength concrete reinforced with recycled rubber particles', Mag. Concr. Res., 63, 3, 187-195 (2011)

36. L.H. Chou, C.N. Lin, C.K. Lu, C.H. Lee, M.T. Lee, Improving rubber concrete by waste organic sulfur compounds, Waste Manag. Res. J. Int. Solid Wastes Public Clean. Assoc. ISWA, 28, 1, 29-35 (2010)

37. N. Segre, I. Joekes, Use of tire rubber particles as addition to cement paste, Cem. Concr. Res., 30, 9,1421-1425 (2000)

38. H. Rostami, J. Lepore, T. Silverstraim, I. Zundi, 'Use of recycled rubber tires in concrete', in Proceedings of the International Conference on Concrete 2000, 391-399 (1993)

39. Z. Haibo, G. O. U. Mifeng, L. I. U. Xiaoxing, G. Xuemao, Effect of Rubber Particle Modification on Properties of Rubberized Concrete, J. Wuhan Univ. Technol. Sci. Ed., 4, 763-768 (2014)

40. C. Albano, N. Camacho, J. Reyes, J. L. Feliu, M. Hernández, Influence of scrap rubber addition to Portland I concrete composites: Destructive and 
non-destructive testing, Compos. Struct., 71, 3-4, 439-446 (2005)

41. M. Balaha, A. Badawy, M. Hashish, Effect of using ground waste tire rubber as fine aggregate on the behaviour of concrete mixes, Indian J. Eng. Mater., 14, 427-435 (2007)

42. L. He, Y. Ma, Q. Liu, Y. Mu, Surface modification of crumb rubber and its influence on the mechanical properties of rubber-cement concrete, Constr. Build. Mater., 120, 403-407, (2016)

43. T. Biel, H. Lee, Magnesium Oxychloride Cement Concrete with Recycled Tire Rubber, Transp. Res. Rec., 1561, 1, 6-12 (1996)

44. M. Gesoğlu, E. Güneyisi, Strength development and chloride penetration in rubberized concretes with and without silica fume, Mater. Struct., 40, 9, 953-964 (2007)

45. E. Güneyisi, M. Gesoğlu, T. Özturan, Properties of rubberized concretes containing silica fume, Cem. Concr. Res., 34, 12, 2309-2317 (2004)

46. M. R. Sohrabi, M. Karbalaie, An Experimental Study on the Compressive Strength of Concrete Containing Crumb Rubber, Int. J. Civ. Environ. Eng., 11, 3 (2011)

47. F. Pelisser, N. Zavarise, T. A. Longo, A. M. Bernardin, Concrete made with recycled tire rubber: Effect of alkaline activation and silica fume addition, J. Clean. Prod., 1-7 (2010)

48. F. Azevedo, F. Pacheco-Torgal, C. Jesus, J. L. Barroso de Aguiar, and A. F. Camões, 'Properties and durability of HPC with tyre rubber wastes', Constr. Build. Mater., 34, 186-191 (2012)

49. M. Bravo, J. de Brito, Concrete made with used tyre aggregate: durability-related performance, $J$. Clean. Prod., 25, 42-50 (2012)

50. T. Gupta, S. Chaudhary, R. K. Sharma, Assessment of mechanical and durability properties of concrete containing waste rubber tire as fine aggregate, Constr. Build. Mater., 73, 562574 (2014)

51. B. S. Thomas, R. C. Gupta, P. Kalla, L. Cseteneyi, Strength, abrasion and permeation characteristics of cement concrete containing discarded rubber fine aggregates, Constr. Build. Mater., 59, 204212 (2014)

52. N. Oikonomou, S. Mavridou, Improvement of chloride ion penetration resistance in cement mortars modified with rubber from worn automobile tires, Cem. Concr. Compos., 31,6, 403-407 (2009)

53. T. Gupta, S. Chaudhary, R. K. Sharma, Mechanical and durability properties of waste rubber fiber concrete with and without silica fume, J. Clean. Prod., 112, 702-711 (2016)
54. O. Onuaguluchi, D. K. Panesar, Hardened properties of concrete mixtures containing precoated crumb rubber and silica fume, J. Clean. Prod., 82, 125-131 (2014)

55. A. J. Kardos, S. A. Durham, Strength, durability, and environmental properties of concrete utilizing recycled tire particles for pavement applications, Constr. Build. Mater., 98, 832-845 (2015)

56. G. Li et al., 'Properties of rubberized concrete modified by using silane coupling agent and carboxylated SBR', J. Clean. Prod., 112, 797-807 (2016)

57. B. S. Thomas, R. C. Gupta, P. Mehra, and S. Kumar, 'Performance of high strength rubberized concrete in aggressive environment', Constr. Build. Mater., 83, 320-326 (2015)

58. R. H. Ghedan, D. M. Hamza, Effect of rubber treatment on compressive strength and thermal conductivity of modified rubberized concrete, $J$. Eng. Dev., 15, 4, 21-29 (2011)

59. B. S. Mohammed, K. M. Anwar Hossain, J. T. Eng Swee, G. Wong, M. Abdullahi, Properties of crumb rubber hollow concrete block, J. Clean. Prod., 23, 1, 57-67 (2012)

60. A. Fiore, G. C. Marano, C. Marti, M. Molfetta, 'On the Fresh/Hardened Properties of Cement Composites Incorporating Rubber Particles from Recycled Tires', Adv. Civ. Eng., 2014, 1-12 (2014)

61. A. Ocholi, S. P. Ejeh, S. M. Yinka, An Investigation into the Thermal Performance of Rubber-Concrete, Acad. J. Interdiscip. Stud., 3, 5, 29 (2014)

62. F. Pacheco-Torgal, Y. Ding, S. Jalali, Properties and durability of concrete containing polymeric wastes (tyre rubber and polyethylene terephthalate bottles): An overview, Constr. Build. Mater., vol. 30, 714-724 (2012)

63. M. Jedidi, A. Boulila, O. Benjeddou, C. Soussi, 'Crumb Rubber Effect on Acoustic Properties of Self-Consolidating Concrete, Int. J. Therm. Environ. Eng., 8, 2, 69-76 (2014)

64. N. Holmes, A. Browne, C. Montague, Acoustic properties of concrete panels with crumb rubber as a fine aggregate replacement, Constr. Build. Mater., 73, 195-204 (2014)

65. E. Fraile-Garcia, J. Ferreiro-Cabello, B. Defez, G. Peris-Fajanes, Acoustic Behavior of Hollow Blocks and Bricks Made of Concrete Doped with Waste-Tire Rubber, Materials, 9,12, 962 (2016) 